\title{
Rapid and persistent suppression of feeding behavior induced by sensitization training in Aplysia
}

\author{
Ama Acheampong, ${ }^{1,2,4}$ Kathleen Kelly, ${ }^{1,3,4}$ Maria Shields-Johnson, ${ }^{1,4}$ Julie Hajovsky, ${ }^{1}$ \\ Marcy Wainwright, ${ }^{1}$ and Riccardo Mozzachiodi ${ }^{1,5}$ \\ ${ }^{1}$ Department of Life Sciences, Texas A\&M University-Corpus Christi, Corpus Christi, Texas 78412, USA; ${ }^{2}$ Houston Community \\ College, Houston, Texas 77002, USA; ${ }^{3}$ Endicott College, Beverly, Massachusetts 01915, USA
}

\begin{abstract}
In Aplysia, noxious stimuli induce sensitization of defensive responses. However, it remains largely unknown whether such stimuli also alter nondefensive behaviors. In this study, we examined the effects of noxious stimuli on feeding. Strong electric shocks, capable of inducing sensitization, also led to the suppression of feeding. The use of multiple training protocols revealed that the time course of the suppression of feeding was analogous to that of sensitization. In addition, the suppression of feeding was present only at the time points in which sensitization was expressed. These results suggest that, in Aplysia, noxious stimuli may produce concurrent changes in neural circuits controlling both defensive and nondefensive behaviors.
\end{abstract}

[Supplemental material is available for this article.]

Sensitization is an elementary form of learned fear in which defensive responses are enhanced following exposure to aversive stimuli (for review, see Carew and Sahley 1986; Brunelli et al. 1997; Kandel 2001; Fioravante et al. 2008). Great progress in understanding the mechanisms of sensitization has been made using the marine mollusk Aplysia californica (for review, see Kandel 2001; Hawkins et al. 2006; Byrne et al. 2009). In Aplysia, strong electric shocks applied to the body wall, which mimic the attack of a predator (Watkins et al. 2010), increase defensive responses, including withdrawal reflexes of the gill, tail, and siphon, and escape locomotion (Stopfer and Carew 1988; Kandel 2001; Byrne et al. 2009). When paired with stimuli such as seawater of altered salinity or $\mathrm{pH}$, strong electric shocks also enhance other defensive responses, including inking and respiratory pumping (Levy and Susswein 1999).

In order to budget its responses following exposure to aversive stimuli, an organism is also required to change the expression of nondefensive behaviors (Kavaliers and Choleris 2001). Interestingly, whereas modifications of defensive responses have been extensively described in Aplysia and other animal models (e.g., Carew and Sahley 1986; Cleary et al. 1995; Frost et al. 1998; Kandel 2001; Zaccardi et al. 2001), the effects of noxious stimuli on nondefensive behaviors have been only marginally explored. Characterizing the effects of noxious stimuli on both defensive and nondefensive behaviors is critical to fully appreciate the means by which encountered stimuli differentially influence the animal's behavioral repertoire.

Early evidence of the effects of noxious stimuli on nondefensive responses in Aplysia was provided by Kupfermann and Pinsker (1968), who reported a reduction of feeding following the delivery of strong electric shocks. However, the effectiveness of the same training protocol to induce changes in defensive responses was not analyzed. Therefore, the goal of this study was to explore whether behaviors of different nature (defensive and nondefen-

\footnotetext{
${ }^{4}$ These authors contributed equally to this work.

${ }^{5}$ Corresponding author.

E-mail riccardo.mozzachiodi@tamucc.edu.

Article is online at http://www.learnmem.org/cgi/doi/10.1101/lm.024638.111.
}

sive) were concurrently altered by exposure to noxious stimuli in Aplysia. In particular, we examined the ability of different protocols of noxious stimulation to induce both sensitization of a defensive reflex and changes in a nondefensive behavior: feeding.

As readouts of a defensive response and feeding, we used the duration of the tail-induced siphon withdrawal reflex (TSWR) and the occurrence of bites, respectively. The TSWR consists of a contraction of the siphon in response to a brief, mild current pulse delivered through a pair of electrodes implanted into one side of the tail (Supplemental Fig. S1A1; see Supplemental Material for details). The duration of the TSWR from the onset of the contraction to the onset of relaxation of the siphon was used as a measure of reflex strength (e.g., Goldsmith and Byrne 1993; Cleary et al. 1998; Wainwright et al. 2002; Antzoulatos et al. 2006; see Supplemental Material for details). Bites consist of rhythmic movements of the radula (Kupfermann 1974; Susswein et al. 1976; Brembs et al. 2002), which are controlled by the activity of a well-characterized neural circuit (for review, see Elliott and Susswein 2002; Cropper et al. 2004). Bites were elicited and counted during a testing period (Supplemental Fig. S1B1; see below and Supplemental Material for details).

Three previously established training protocols were employed to analyze the effect of noxious stimuli on TSWR and feeding: (1) single-trial training, (2) brief shock treatment, and (3) long-term sensitization training (see Supplemental Material for detailed description of the protocols).

We first employed a single-trial training, consisting of one 10 -sec train of electric shocks, delivered to the lateral body wall (60-mA maximal intensity, 500-msec impulses, $1 \mathrm{~Hz}$ ) (Supplemental Fig. S1A1,A2). The single-trial training induces sensitization, which manifests as an increased duration of the TSWR on the side of the animal that received the training (Byrne et al. 1991; Fernandez et al. 2003). The effects of the single-trial training were examined at $15 \mathrm{~min}, 2 \mathrm{~h}$, and $24 \mathrm{~h}$ after treatment in trained and untrained (control) animals (Supplemental Fig. S1A2,B2). We initially characterized the time course of the sensitization of the TSWR induced by the single-trial training. For each time point, the change in TSWR duration (i.e., [post-test TSWR duration]/ [pretest TSWR duration]) was calculated to assess modifications 
in the reflex strength due to treatment (e.g., Goldsmith and Byrne 1993; Cleary et al. 1998; Antzoulatos et al. 2006). Data were compared between trained and untrained animals at each time point (Wainwright et al. 2002; Antzoulatos et al. 2006; Miniaci et al. 2008), using the Mann-Whitney U-test. All values are reported as means \pm SEM. The change in TSWR duration was significantly greater in trained animals as compared to untrained controls at both 15 min (trained: $3.75 \pm 2.14, n=8$; untrained: $0.97 \pm 0.13$, $n=9 ; P<0.05$ ) (Fig. 1A1) and $2 \mathrm{~h}$ after treatment (trained: $6.16 \pm 2.78, n=8$; untrained: $1.28 \pm 0.37, n=9 ; P<0.05$ ) (Fig. $1 \mathrm{~A} 2$ ). However, by $24 \mathrm{~h}$ after treatment, the change in TSWR duration was no longer significantly different between trained and untrained animals (trained: $1.66 \pm 0.73, n=7$; untrained: $1.84 \pm$ $0.59, n=7 ; P=0.81$ ) (Fig. 1A3). These results indicate that the single-trial training produced rapid, persistent, but not long-term sensitization of the TSWR. Sensitization with a similar temporal profile has been previously reported following a training protocol consisting of five shocks spaced $1 \mathrm{sec}$ apart (Sutton et al. 2002).

In a separate group of animals, we next examined whether the single-trial training altered the expression of a nondefensive behavior: feeding (see Supplemental Material for details). Feeding was assessed by counting the number of bites generated during a 5-min testing period (i.e., biting test), in which animals were placed in a solution of aquarium seawater containing seaweed extract (Supplemental Fig. S1B1). The seaweed extract provides a tonic chemical stimulus, which readily elicits bites (see Supplemental Material for details; Brembs et al. 2002). Biting tests were conducted before (pretest) and $15 \mathrm{~min}, 2 \mathrm{~h}$, and $24 \mathrm{~h}$ after treatment (post-tests) (Supplemental Fig. S1B2). Treatmentinduced changes in feeding were analyzed as a difference in the number of generated bites (i.e., bites during post-test minus bites during pretest) (Lechner et al. 2000; Lorenzetti et al. 2006).
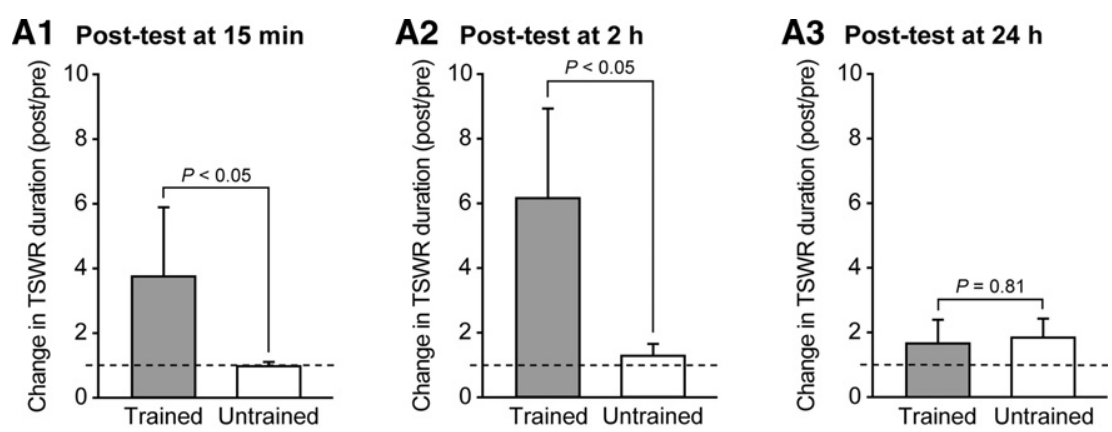

\section{B1 Post-test at $15 \mathrm{~min}$}

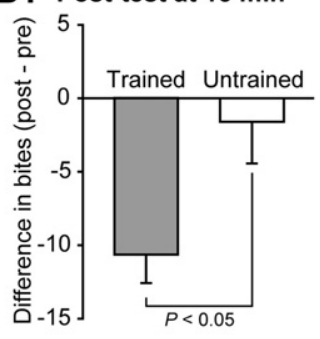

B2 Post-test at $2 \mathrm{~h}$

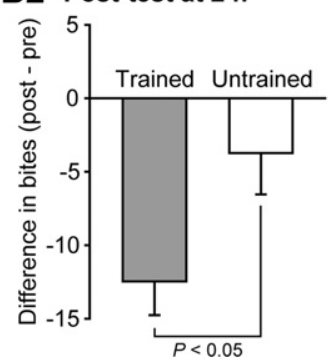

B3 Post-test at $24 \mathrm{~h}$

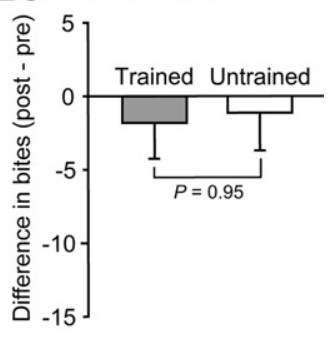

Figure 1. Single-trial training produced sensitization of the TSWR and suppression of feeding with similar time courses. (A) The single-trial training produced sensitization of the TSWR, which was observed at $15 \mathrm{~min}(A 1)$ and $2 \mathrm{~h}(A 2)$ but not at $24 \mathrm{~h}$ after treatment $(A 3)$. (B) The single-trial training produced suppression of feeding, which was observed at $15 \mathrm{~min}$ (B1) and $2 \mathrm{~h}$ (B2) but not at $24 \mathrm{~h}$ after treatment $(B 3)$. In this and in the following figures, data from trained and untrained animals were expressed as mean \pm SEM and were compared at each time point using the Mann-Whitney U-test. Statistical significance was set at $P<0.05$.
The difference in bites was compared between trained and untrained animals at each time point, using the Mann-Whitney Trained animals showed a significant decrease in the number of bites compared to untrained controls at both $15 \mathrm{~min}$ (trained: $-10.67 \pm 1.94$ bites, $n=15$; untrained: $-1.60 \pm 2.84$ bites, $n=15 ; P<0.05$ ) (Fig. 1B1) and $2 \mathrm{~h}$ after treatment (trained: $-12.47 \pm 2.29$ bites, $n=15$; untrained: $-3.73 \pm 2.81$ bites, $n=$ $15, P<0.0)$ (Fig. 1B2). However, by $24 \mathrm{~h}$ after treatment, the difference in bites was no longer significantly different between trained and untrained animals (trained: $-1.80 \pm 2.36$ bites, $n=$ These results indicate that the single-trial training produced a suppression of feeding (Fig. 1B1,B2) with a time course that paralleled

In the next series of experiments, we explored whether the expression of sensitization was a requirement for the occurrence of the suppression of feeding. As a training protocol, we employed within 25 min of the treatment (Antzoulatos et al. 2006). BST consisted of a 2-sec train of AC electric shocks, delivered to the lateral (60-mA maximal intensity, 500-msec impulses, $1 \mathrm{~Hz}$ ) Supplemental Fig. S2A1). Using two series of experiments, we exConed the effects of BST on the TSWR and feeding, respectively. induce sensitization 15 min after training (change in TSWR untrained: $1.14 \pm 0.17, n=8 ; P=0.28$ ) (Fig. 2A1). Similarly, feeding was not significantly altered $15 \mathrm{~min}$ after BST (difference in bites, trained: $0.50 \pm 2.83$ bites, $n=8$; difference in bites, untrained: $-2.33 \pm 1.05, n=9 ; P=0.63$ ) (Fig. 2B1). Interestingly, $2 \mathrm{~h}$ after BST treatment, both sensitization (change in TSWR duration, trained: $3.80 \pm 1.38, n=7$; change in TSWR duration, untrained: $1.24 \pm 0.23, n=8 ; P<0.05$ ) (Fig. 2A2) and suppression of feeding (difference in bites, trained: $-5.75 \pm$ 3.20 bites, $n=8$; difference in bites, untrained: $-0.67 \pm 1.14, n=9 ; \quad P<0.05$ ) (Fig. 2B2) were observed.

These findings indicate that, following BST, feeding was not changed at a time point in which sensitization was not observed (15 min) (Fig. 2A1,B1) but was suppressed at the time point in which sensitization was expressed $(2 \mathrm{~h})$ (Fig. 2A2,B2), further demonstrating the temporal relation between these two behavioral changes. The concurrent presence/absence of both sensitization and suppression of feeding at different time points suggests a mechanistic relation between these two behavioral changes.

In Aplysia, extended training with repeated presentations of noxious stimuli produces enduring forms of sensitization (e.g., Pinsker et al. 1973; Frost et al. 1985; Cleary et al. 1998, Sutton et al. 2002; Wainwright et al. 2002; Khabour et al. 2004). Does extended training also induce long-lasting suppression of feeding? To address this question, we used a training paradigm that induces sensitization of the TSWR persisting for at least $24 \mathrm{~h}$ (long-term sensitization; LTS) (Cleary et al. 1998; Khabour et al. 2004). In this series of experiments, TSWR and feeding were measured in 

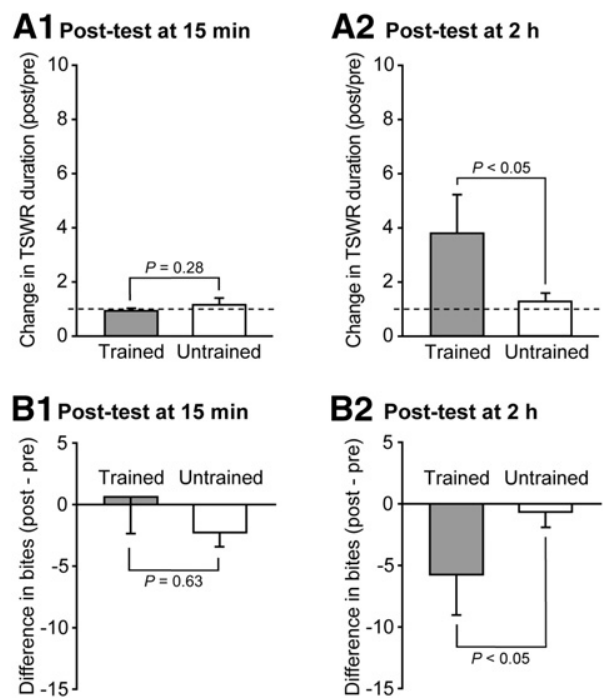

Figure 2. A brief shock treatment (BST) produced delayed sensitization of the TSWR and suppression of feeding $2 \mathrm{~h}$ after treatment. (A) BST did not produce sensitization of the TSWR at 15 min post-treatment (A1) but induced sensitization at $2 \mathrm{~h}$ post-treatment $(A 2)$. (B) BST did not suppress feeding at 15 min post-treatment (B1) but induced a suppression of feeding at $2 \mathrm{~h}$ post-treatment (B2).

the same animals prior to (pretest) and $24 \mathrm{~h}$ after treatment (posttest) with training or control protocols (Supplemental Fig. S3; see Supplemental Material for details). The LTS training consisted of four trials of electric shocks, each identical to the single-trial training, spaced 30 min apart (Supplemental Fig. S3; Scholz and Byrne 1987; Cleary et al. 1998; Wainwright et al. 2002). Twenty-four hours after treatment, both LTS (change in TSWR duration, trained: $5.68 \pm 2.71, n=5$; change in TSWR duration, untrained: $0.95 \pm 0.29, n=5 ; P<0.05$ ) (Fig. 3A) and suppression of feeding (difference in bites, trained: $-13.40 \pm 4.08$ bites, $n=5$; difference in bites, untrained: $-1.80 \pm 1.20, n=5 ; P<0.05$ ) (Fig. 3B) were observed, demonstrating that the two behavioral changes were coexpressed at 24 -h post-test.

The data collected using three training protocols indicate that, similar to sensitization, the duration of the suppression of feeding depends on the amount of training received, with LTS training producing more enduring suppression (Fig. 3) than single-trial protocols (Figs. 1, 2). However, it must be noted that the magnitude of feeding suppression produced by the three employed protocols (single-trial training at $2 \mathrm{~h}$, BST at $2 \mathrm{~h}$, and LTS training at $24 \mathrm{~h}$ ) was not significantly different (Kruskall-Wallis test, $\left.H_{2}=1.762, P=0.414\right)$, thus indicating that the amount of training does not alter feeding in an additive manner.

Overall, the findings reported in this study indicate that noxious stimuli produce distinct and concomitant changes in two behaviors of Aplysia, sensitization of a withdrawal reflex and suppression of feeding. The tight temporal link between sensitization and suppression of feeding (Figs. 1-3) and the expression of sensitization as a requirement for the occurrence of the suppression of feeding (Fig. 2) suggest that these two behavioral changes are mechanistically related.

From a neuroethological point of view, the concurrent strengthening of defensive reflexes and the suppression of nondefensive behaviors, such as feeding, is a logical adaptive response to an aversive event (Gillette et al. 2000; Kavaliers and Choleris 2001) and provides an interesting example of differential modulation of multiple behaviors by an external stimulus. Although previous work has examined possible ways by which multiple be- haviors are controlled (behaviors controlled in parallel by a common intervening variable vs. behaviors modulated individually) (e.g., Miller 1959; Walters et al. 1981; Cleary and Byrne 1993; Nedvetzki et al. 1998; Gillette et al. 2000), further investigation is required, in particular to combine behavioral, cellular, and biochemical results in order to provide a comprehensive description of this process. The concurrent modulation of a defensive reflex and feeding by noxious stimuli in Aplysia offers an excellent opportunity to examine the mechanisms of multiple control of behavior in a model system, which is tractable at the circuit, single-cell, and biochemical levels.

The differential effect of noxious stimuli on the TSWR (augmented [Figs. 1A, 2A, 3A]) and feeding (suppressed [Figs. 1B, 2B, 3B]) in Aplysia is consistent with the view of a central arousal system that optimizes behavioral outputs through the concurrent modulation of defensive and nondefensive responses (Walters et al. 1981). The analogous temporal dynamics exhibited by the two behavioral modifications would support the hypothesis of a modulator(s) that, released by noxious stimuli, concomitantly alters the neural circuits controlling the TSWR and feeding. The neurotransmitter serotonin (5-HT) is a potential candidate as a biochemical link connecting the noxious stimuli to the two observed behavioral modifications. 5-HT is released into the hemolymph and into the neuropil following strong electric stimulation of the body wall (Levenson et al. 1999) or after peripheral nerve shock (Marinesco and Carew 2002). Notably, 5-HT plays a key role in mediating changes in the withdrawal reflexes circuits underlying sensitization in Aplysia (e.g., Brunelli et al. 1976; Walters et al. 1983; Glanzman et al. 1989; Sugita et al. 1997; Levenson et al. 1999; Marinesco and Carew 2002; Marinesco et al. 2004a,b). 5-HT also contributes to the modulation of the feeding at both behavioral and cellular levels (e.g., Weiss et al. 1978; Kupfermann and Weiss 1982; Alexeeva et al. 1998; Levenson et al. 1999; Kabotyanski et al. 2000), although its modulatory role in the feeding neural circuit is less clear. Indeed, 5-HT appears to be capable of both increasing and decreasing the activity of the feeding neural circuit. For example, the serotonergic metacerebral cells (MCCs) mediate aspects of food-induced arousal (Weiss et al. 1978; Kupfermann and Weiss 1982; Rosen et al.
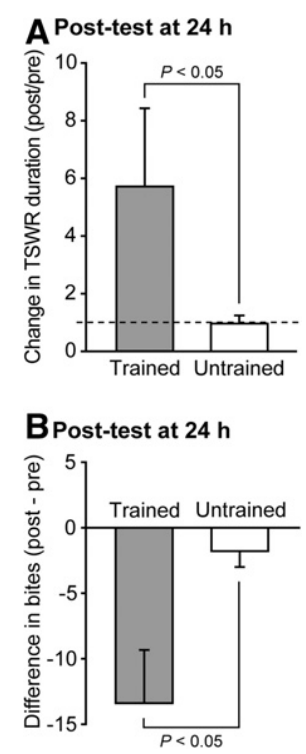

Figure 3. A long-term sensitization (LTS) training produced LTS of the TSWR $(A)$ and long-term suppression of feeding $(B)$. Both behavioral changes were expressed within the same animals $24 \mathrm{~h}$ after treatment. 
1989), whereas application of 5-HT to the isolated buccal ganglion reduces the excitability and the plateau-like potential of patterninitiation neuron B31/32 (Susswein and Byrne 1988; Kabotyanski et al. 2000). Albeit complex, the role of 5-HT as a component of the training-induced biochemical pathway leading to changes in different neural circuits is intriguing and warrants future investigation.

The expression of the suppression of feeding in a long-term form (Fig. 3) provides the framework for the characterization of its underlying cellular mechanisms, as it would allow us to identify the cellular sites of plasticity within the feeding neural circuit, while the effects of LTS training persist. Modifications at the level of the decision-making neuron B51, which is critical to bias the feeding neural circuit to generate the neurophysiological activity associated with bites (Plummer and Kirk 1990; Nargeot et al. 1999a,b; Mozzachiodi and Byrne 2010; Nargeot and Simmers 2011), may contribute, at least in part, to the suppression of feeding produced by LTS training. In addition, pattern-initiating neurons B31/32 and B63 (Susswein and Byrne 1988; Hurwitz et al. 1997) are two other putative loci of plasticity that may play a role in the suppression of feeding observed following LTS training.

In conclusion, our findings lay the foundation for a mechanistic analysis of the effects of noxious stimulation on the neural circuits underlying nondefensive behaviors, which, combined with the current knowledge of the cellular underpinnings of sensitization, would help understand how aversive experience shapes the animal's behavioral repertoire.

\section{Acknowledgments}

This work was supported by start-up funds from the College of Science and Technology to R.M. and by a grant to R.M. and M.W. from the Texas Research Development Funds. A.A. and K.K. were supported by the DOD/NSF Research Experiences for Undergraduates grant 0453329. M.S.-J. was supported by NIH EARDA grant 5G11HD046353-05. We thank Drs. Douglas Baxter, Leonard Cleary, and Gregg Phares for helpful comments on an earlier draft of the manuscript. We also thank Max Odem and Harris Weisz (Texas A\&M University-Corpus Christi) for conducting some of the behavioral experiments using the BST protocol.

\section{References}

Alexeeva V, Borovikov D, Miller MW, Rosen SC, Cropper EC. 1998. Effect of a serotonergic extrinsic modulatory neuron (MCC) on radula mechanoafferent function in Aplysia. J Neurophysiol 80: 1609-1622.

Antzoulatos EG, Wainwright ML, Cleary LJ, Byrne JH. 2006. Long-term sensitization training primes Aplysia for further learning. Learn Mem 13: $422-425$.

Brembs B, Lorenzetti FD, Reyes FD, Baxter DA, Byrne JH. 2002. Operant reward learning in Aplysia: Neuronal correlates and mechanisms. Science 296: 1706-1709.

Brunelli M, Castellucci V, Kandel ER. 1976. Synaptic facilitation and behavioral sensitization in Aplysia: Possible role of serotonin and cyclic AMP. Science 194: 1178-1181.

Brunelli M, Garcia-Gil M, Mozzachiodi R, Scuri R, Zaccardi ML. 1997. Neurobiological principles of learning and memory. Arch Ital Biol 135: $15-36$.

Byrne JH, Baxter DA, Buonomano DV, Cleary LJ, Eskin A, Goldsmith JR, McLendon E, Nazif FN, Noel F, Scholz KP. 1991. Neural and molecular bases of nonassociative and associative learning in Aplysia. Ann NY Acad Sci 627: 124-149.

Byrne JH, Antzoulatos EG, Fioravante D. 2009. Learning and memory in invertebrates: Aplysia. In Encyclopedia of neuroscience (ed. LR Squire), pp. 405-412. Academic Press, Oxford.

Carew TJ, Sahley CL. 1986. Invertebrate learning and memory: From behavior to molecules. Annu Rev Neurosci 9: 435-487.

Cleary LJ, Byrne JH. 1993. Identification and characterization of a multifunction neuron contributing to defensive arousal in Aplysia. J Neurophysiol 70: $1767-1776$.

Cleary LJ, Byrne JH, Frost WN. 1995. Role of interneurons in defensive withdrawal reflexes in Aplysia. Learn Mem 2: 133-151.
Cleary LJ, Lee WL, Byrne JH. 1998. Cellular correlates of long-term sensitization in Aplysia. J Neurosci 18: 5988-5998.

Cropper EC, Evans CG, Hurwitz I, Jing J, Proekt A, Romero A, Rosen SC. 2004. Feeding neural networks in the mollusc Aplysia. Neurosignals 13: $70-86$.

Elliott CJ, Susswein AJ. 2002. Comparative neuroethology of feeding control in molluscs. J Exp Biol 205: 877-896.

Fernandez RI, Lyons LC, Levenson J, Khabour O, Eskin A. 2003. Circadian modulation of long-term sensitization in Aplysia. Proc Natl Acad Sci 100: $14415-14420$.

Fioravante D, Antzoulatos EG, Byrne JH. 2008. Sensitization and habituation: Invertebrate. In Learning and memory: A comprehensive reference (ed. JH Byrne), pp. 31-51. Academic Press, Oxford.

Frost WN, Castellucci VF, Hawkins RD, Kandel ER. 1985. Monosynaptic connections made by the sensory neurons of the gill- and siphon-withdrawal reflex in Aplysia participate in the storage of long-term memory for sensitization. Proc Natl Acad Sci 82: 8266-8269.

Frost WN, Brandon CL, Mongeluzi DL. 1998. Sensitization of the Tritonia escape swim. Neurobiol Learn Mem 69: 126-135.

Gillette R, Huang RC, Hatcher N, Moroz LL. 2000. Cost-benefit analysis potential in feeding behavior of a predatory snail by integration of hunger, taste, and pain. Proc Natl Acad Sci 97: 3585-3590.

Glanzman DL, Mackey SL, Hawkins RD, Dyke AM, Lloyd PE, Kandel ER. 1989. Depletion of serotonin in the nervous system of Aplysia reduces the behavioral enhancement of gill withdrawal as well as the heterosynaptic facilitation produced by tail shock. J Neurosci 9: 4200-4213.

Goldsmith JR, Byrne JH. 1993. Bag cell extract inhibits tail-siphon withdrawal reflex, suppresses long-term but not short-term sensitization, and attenuates sensory-to-motor neuron synapses in Aplysia. J Neurosci 13: 1688-1700.

Hawkins RD, Kandel ER, Bailey CH. 2006. Molecular mechanisms of memory storage in Aplysia. Biol Bull 210: 174-191.

Hurwitz I, Kupfermann I, Susswein AJ. 1997. Different roles of neurons B63 and B34 that are active during the protraction phase of buccal motor programs in Aplysia californica. J Neurophysiol 78: 1305-1319.

Kabotyanski EA, Baxter DA, Cushman SJ, Byrne JH. 2000. Modulation of fictive feeding by dopamine and serotonin in Aplysia. J Neurophysiol 83: 374-392.

Kandel ER. 2001. The molecular biology of memory storage: A dialog between genes and synapses. Science 294: 1030-1038.

Kavaliers M, Choleris E. 2001. Antipredator responses and defensive behavior: Ecological and ethological approaches for the neurosciences. Neurosci Biobehav Rev 25: 577-586.

Khabour O, Levenson J, Lyons LC, Kategaya LS, Chin J, Byrne JH, Eskin A. 2004. Coregulation of glutamate uptake and long-term sensitization in Aplysia. J Neurosci 24: 8829-8837.

Kupfermann I. 1974. Feeding behavior in Aplysia: A simple system for the study of motivation. Behav Biol 10: 1-26.

Kupfermann I, Pinsker H. 1968. A behavioral modification of the feeding reflex in Aplysia californica. Commun Behav Biol 2: 13-17.

Kupfermann I, Weiss KR. 1982. Activity of an identified serotonergic neuron in free moving Aplysia correlates with behavioral arousal. Brain Res 241: 334-337.

Lechner HA, Baxter DA, Byrne JH. 2000. Classical conditioning of feeding in Aplysia: I. Behavioral analysis. J Neurosci 20: 3369-3376.

Levenson J, Byrne JH, Eskin A. 1999. Levels of serotonin in the hemolymph of Aplysia are modulated by light/dark cycles and sensitization training. J Neurosci 19: 8094-8103.

Levy M, Susswein AJ. 1999. Separate effects of a classical conditioning procedure on respiratory pumping, swimming, and inking in Aplysia fasciata. Learn Mem 6: 21-36.

Lorenzetti FD, Mozzachiodi R, Baxter DA, Byrne JH. 2006. Classical and operant conditioning differentially modify the intrinsic properties of an identified neuron. Nat Neurosci 9: 17-19.

Marinesco S, Carew TJ. 2002. Serotonin release evoked by tail nerve stimulation in the CNS of Aplysia: Characterization and relationship to heterosynaptic plasticity. J Neurosci 22: 2299-2312.

Marinesco S, Kolkman KE, Carew TJ. 2004a. Serotonergic modulation in Aplysia. I. Distributed serotonergic network persistently activated by sensitizing stimuli. J Neurophysiol 92: 2468-2486.

Marinesco S, Wickremasinghe N, Kolkman KE, Carew TJ. 2004b. Serotonergic modulation in Aplysia. II. Cellular and behavioral consequences of increased serotonergic tone. J Neurophysiol 92: 2487-2496.

Miller N. 1959. Liberalization of basic H-R concepts: Extensions to conflict behavior, motivation and social learning. In Psychology: A study of a science, Study 1, Vol. 2 (ed. S Koch), pp. 196-292. McGraw-Hill, New York.

Miniaci MC, Kim JH, Puthanveettil SV, Si K, Zhu H, Kandel ER, Bailey CH. 2008. Sustained CPEB-dependent local protein synthesis is required to stabilize synaptic growth for persistence of long-term facilitation in Aplysia. Neuron 59: 1024-1036. 
Mozzachiodi R, Byrne JH. 2010. More than synaptic plasticity: Role of nonsynaptic plasticity in learning and memory. Trends Neurosci 33: $17-26$.

Nargeot R, Simmers J. 2011. Neural mechanisms of operant conditioning and learning-induced behavioral plasticity in Aplysia. Cell Mol Life Sci 68: $803-816$.

Nargeot R, Baxter DA, Byrne JH. 1999a. In vitro analog of operant conditioning in Aplysia. I. Contingent reinforcement modifies the functional dynamics of an identified neuron. J Neurosci 19: 2247-2260.

Nargeot R, Baxter DA, Byrne JH. 1999b. In vitro analog of operant conditioning in Aplysia. II. Modifications of the functional dynamics of an identified neuron contribute to motor pattern selection. J Neurosci 19: $2261-2272$.

Nedvetzki Y, Markovich S, Susswein AJ. 1998. Inhibition of mating in Aplysia fasciata by food stimuli in the environment, but not by postingestion stimuli causing satiation. J Comp Physiol [A] 182: 183-190.

Pinsker HM, Hening WA, Carew TJ, Kandel ER. 1973. Long-term sensitization of a defensive withdrawal reflex in Aplysia. Science 182: 1039-1042.

Plummer MR, Kirk MD. 1990. Premotor neurons B51 and B52 in the buccal ganglia of Aplysia californica: Synaptic connections, effects on ongoing motor rhythms, and peptide modulation. J Neurophysiol 63: 539-558.

Rosen SC, Weiss KR, Goldstein RS, Kupfermann I. 1989. The role of a modulatory neuron in feeding and satiation in Aplysia: Effects of lesioning of the serotonergic metacerebral cells. J Neurosci 9: $1562-1578$

Scholz KP, Byrne JH. 1987. Long-term sensitization in Aplysia: Biophysical correlates in tail sensory neurons. Science 235: 685-687.

Stopfer S, Carew TJ. 1988. Development of sensitization in the escape locomotion system in Aplysia. J Neurosci 8: 223-230.
Sugita S, Baxter DA, Byrne JH. 1997. Differential effects of 4-aminopyridine, serotonin, and phorbol esters on facilitation of sensorimotor connections in Aplysia. J Neurophysiol 77: 177-185.

Susswein AJ, Byrne JH. 1988. Identification and characterization of neurons initiating patterned activity in the buccal ganglia of Aplysia.J Neurosci 8: 2049-2061.

Susswein AJ, Kupfermann I, Weiss KR. 1976. The stimulus control of biting in Aplysia. J Comp Physiol [A] 108: 75-96.

Sutton MA, Ide J, Masters SE, Carew TJ. 2002. Interaction between amount and pattern of training in the induction of intermediate- and long-term memory for sensitization in Aplysia. Learn Mem 9: 29-40.

Wainwright ML, Zhang H, Byrne JH, Cleary LJ. 2002. Localized neuronal outgrowth induced by long-term sensitization training in Aplysia. J Neurosci 22: 4132-4141.

Walters ET, Carew TJ, Kandel ER. 1981. Associative learning in Aplysia: Evidence for conditioned fear in an invertebrate. Science 211: 506-504. Walters ET, Byrne JH, Carew TJ, Kandel ER. 1983. Mechanoafferent neurons innervating tail of Aplysia. II. Modulation by sensitizing stimulation. J Neurophysiol 50: 1543-1559.

Watkins AJ, Goldstein DA, Lee LC, Pepino CJ, Tillett SL, Ross FE, Wilder EM, Zachary VA, Wright WG. 2010. Lobster attack induces sensitization in the sea hare, Aplysia californica. J Neurosci 30: 11028-11031.

Weiss KR, Cohen JL, Kupfermann I. 1978. Modulatory control of buccal musculature by a serotonergic neuron (metacerebral cell) in Aplysia. J Neurophysiol 41: 181-203.

Zaccardi ML, Traina G, Cataldo E, Brunelli M. 2001. Nonassociative learning in the leech Hirudo medicinalis. Behav Brain Res 126: 81-92.

Received October 22, 2011; accepted in revised form February 16, 2012. 


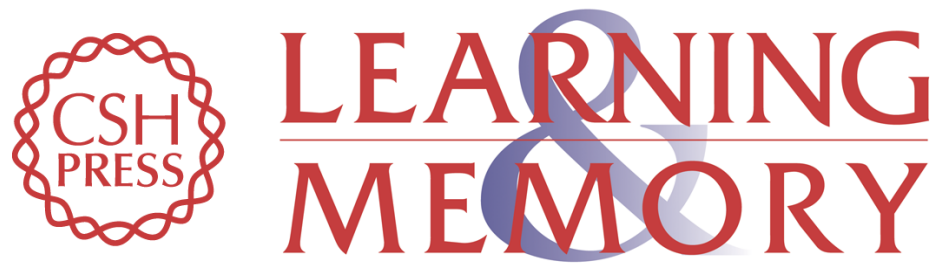

\section{Rapid and persistent suppression of feeding behavior induced by sensitization training in Aplysia}

Ama Acheampong, Kathleen Kelly, Maria Shields-Johnson, et al.

Learn. Mem. 2012, 19:

Access the most recent version at doi:10.1101//m.024638.111

Supplemental http://learnmem.cshlp.org/content/suppl/2012/03/14/19.4.159.DC1
Material

References This article cites 56 articles, 28 of which can be accessed free at: http://learnmem.cshlp.org/content/19/4/159.full.html\#ref-list-1

License

Email Alerting Receive free email alerts when new articles cite this article - sign up in the box at the Service top right corner of the article or click here. 